\title{
Effect of Ultraviolet-C Treatment on Enzymes and Nutritional Properties of Tender Coconut Water
}

\author{
Shivashankar Sanganamoni*, Soumya Purohit and P. Srinivasa Rao \\ Agricultural and Food Engineering Department \\ Indian Institute of Technology, Kharagpur - 721 302, West Bengal, India \\ *Corresponding author
}

\begin{tabular}{|c|c|}
\hline & A B S T R A C T \\
\hline & \multirow{6}{*}{$\begin{array}{l}\text { The effect of ultraviolet (UV-C) treatment on enzymes (viz. Polyphenol oxidase and } \\
\text { Peroxidase) and nutritional properties (viz. Ascorbic acid, Antioxidant activity and Total } \\
\text { phenolic content) of tender coconut water (Cocos nucifera) were studied during this } \\
\text { research work. The process conditions for ultraviolet treatment were sample thickness ( } 1 \text {, } \\
2,3 \mathrm{~mm} \text { ), treatment time }(30,60,90 \mathrm{~min}) \text { and distance of sample from lamp source }(8.6 \text {, } \\
13.7,18.6 \mathrm{~cm} \text { ). The results obtained from this study showed that the UV- C treatment } \\
\text { conditions had significant effect ( } p<0.0001 \text { ) on ascorbic acid, total phenolic content, } \\
\text { antioxidant capacity, PPO and POD of TCW. The maximum inactivation of PPO was } \\
\text { achieved to be } 51.5 \% \text { in ultraviolet treatment, and the maximum inactivation of POD in } \\
\text { ultraviolet treatment was65.7\%. The obtained results evident, that the PPO was most } \\
\text { resistant enzyme to UV light. Further, the results were compared with the thermal } \\
\text { treatment of tender coconut water which is conducted as a part of this experiment and } \\
\text { observed that, maximum inactivation of PPO and POD was achieved in thermal treatment } \\
\text { than ultraviolet treatment. In contrast, the deterioration of nutritional properties in thermal } \\
\text { treatment was high as compared to ultraviolet treatment. The obtained results suggested } \\
\text { that, although the thermal treatment was better processing option pertaining to enzyme } \\
\text { inactivation, but ultraviolet treatment was found superior based on retention of nutritional } \\
\text { attributes. }\end{array}$} \\
\hline Keywor & \\
\hline $\begin{array}{l}\text { ut } \\
\text { olet } \\
\text { O, } \\
\text { nenols }\end{array}$ & \\
\hline Articl & \\
\hline & \\
\hline & \\
\hline
\end{tabular}

\section{Introduction}

Coconut (Cocos nucifera L.) is perennial plant that flowers year round and belongs to the family of the "Arecaceae". Coconut is important fruit tree that provides food for millions of peoples and with its many uses it is popularly known as "Tree of Life" (Chan et al., 2006).

The edible part of coconut fruit (coconut meat and water) is the endosperm tissue. Endosperm tissue undergoes one of three main modes of development namely nuclear, cellular, helobial (Lopes et al., 1993). Inside each coconut's outer shell is a white meaty layer, and inside that is the central cavity (Gabriel, 2009). This central cavity is coated with a jelly-like substance. This jelly is translucent and very soft when the coconut is young (Jackson et al., 2004). The cavity is filled up with a liquid endosperm, which is cytoplasmic in origin (Yong et al., 2009). This cavity can be filled with up to $600 \mathrm{ml}$ of liquid (Chowdhury et al., 2005). Yong et al., (2009) stated that the liquid part of the 
coconut's endosperm is the coconut water $(\mathrm{CW})$ or coconut juice.

Coconut water is a sweet clear liquid, filled in nut when the nut is 5 to 6 months old. Coconut water is tropical fruit juice, highly valued and consumed in tropical areas since it is tasty and has desirable nutritional and therapeutic properties. Indonesia, the Philippines, and India are the largest producers of coconut in the world. Coconut water has been called the "fluid of life" due to its medicinal benefits such as oral rehydration, treatment of childhood diarrhea, gastroenteritis and cholera (Kuberski, 1980; Carpenter and others 1964). It is high in electrolyte content and has been reported as an isotonic beverage due to its balanced electrolytes like sodium and potassium that help restore losses of electrolytes through skin and urinary pathways. Coconut water was claimed as a natural contender in the sports drink market with its delicate aroma, taste and nutritional characteristics together with the functional characteristics required in a sports drink [Food and Agricultural Organization (FAO) 2005].

Generally, the tender coconut water present inside the fruit is shelf sterile and stable for few days (Yong et al., 2009), but shelf life of extracted tender coconut water is very less. The spoilage of extracted TCW mainly due to the presence of enzymes, belonging to oxidase family (Polyphenol oxidase and Peroxidase), that in contact with atmospheric oxygen. The oxidative enzymes have high thermal resistance and their activity leads to yellow, brown or even pink colouring during storage, even under refrigeration.

Polyphenol oxidase (PPO) and Peroxidase (POD) are widely detected in many fruits and vegetables and are closely linked to enzymatic color changes with consequently loose on sensorial properties (Campos et al.,
1996). According to some food technologists, Polyphenol oxidase is indirectly responsible for fruit and vegetables enzymatic browning, it catalyzes two types of oxidative reactions. Such as hydroxylation of monophenols to odiphenols, and the oxidation of this last one colorless compound to highly colored oquinones.

Presently thermal treatment is most commonly applied for inactivating enzymes in coconut water. But the thermal treatment leads to destruction of heat sensitive nutrients which restricts its application for processing of coconut water. Besides the loss of nutrients, it also shows a detrimental effect on color and flavor.

Alternative methods are high pressure application, pulsed electric field, irradiation, and aseptic packaging. However, there are some disadvantages of these techniques in terms of cost, loss of ascorbic and some other quality attributes.

Considering these limitations of other techniques, UV-Cradiation can be used as an alternative method for processing and preservation of TCW. This process does not produce chemical residues (Canitez, 2002). Besides, it is a low-cost operation and effective against many microorganisms (Bintsis et al., 2000) and enzymes.

UV Light is the part of electromagnetic spectrum with wave lengths ranges from 100 $400 \mathrm{~nm}$. UV light is traditionally subdivided into three categories (viz. UV-A, UV-B and UV-C). UV-C is used for surface disinfection of different fruits and other processing equipment. Application of UV light on various liquid foods like apple cider, orange juice, grape juice, milk and honey have been reported recently. Germicidal properties UV$\mathrm{C}$ is due to the absorption of the UV-light by DNA, which causes formation of thymine 
dimer in the same DNA strand (Miller et al., 1999). Due to this, the DNA transcription and replication is blocked, which compromises cellular functions and leads to cell death (Miller et al., 1999). The penetration depth of UV light in coconut water is more because of the UV absorption coefficient of coconut water is less, thus it facilitates UV rays to pass through it.

By considering all above factors, the present study was aimed to study the effect of UV-C treatment on enzymes and nutritional properties of tender coconut water.

\section{Materials and Methods}

\section{Procurement of Tender Coconut Water (TCW)}

6-8 months matured tender coconut fruits of approximately same size contained coconut flesh (jelly like) less than $2 \mathrm{~mm}$ and without any visible damage on outside were purchased from local market at IIT Kharagpur. Surface of coconut husk was properly cleaned with distilled water followed by $1 \%$ sodium hypochlorite sanitize solution (Walter et al., 2009). After, the coconuts were placed in laminar flow UV light chamber for 30 min to make coconuts free from surface contamination.

Tender coconut water was manually extracted from coconut fruit using free washed and sanitized sharp stainless steel, and filtered through muslin cloth. The filtered TCW obtained from several fruits (4-5 coconut fruits having same maturity level) was mixed in a glass beaker.

The mixed TCW was filled and packed in LDPE (low density polyethylene) pouches and immediately stored at $-18 \mathrm{C}$ before use. Whole TCW extracted from fruit was processed on the same day of extraction.

\section{Chemicals and reagents}

All the chemicals and reagents used in the study were analytical grade and procured from Merck, India and Sigma-Aldrich, Germany.

\section{UV-C treatment of tender coconut water}

The tender coconut water was processed using batch type UV-C apparatus designed and fabricated at IIT Kharagpur with proper development. The system was designed such a way that, the distance of sample from lamp source can be varied. Three $18 \mathrm{~W}$ low pressure mercury vapor UV lamp which emits the UV-C light continuously in the wave length ranges from 200-300 $\mathrm{nm}$ were mounted at the top of treatment chamber. Time of UV-C exposure was controlled using a manually operated control switch.

Measured quantity of TCW was poured in $150 \mathrm{~mm}$ standard size petri plates and placed at the center of holder platform (used for maintain different distances between sample and lamp source). Different thickness of sample was maintained by changing the quantity of sample in petri plates. To prevent the exposure of UV light to human skin, a cover was placed in front of the system.

\section{Experimental design}

Full factorial design with 3 replications was followed throughout the experiment. The independent variables viz. Treatment time $(\mathrm{t}-$ $15,30,45,60,75$ and $90 \mathrm{~min}$ ), Distance from lamp source $(\mathrm{H}-8.6,13.7,18.6 \mathrm{~cm})$ and Sample thickness $(\mathrm{x}-1,2,3 \mathrm{~cm})$ were selected with three levels of each of independent variables and their combinations had been investigated for each attribute. After each experiment, PPO, POD activity and nutritional properties (Viz. Ascorbic acid, Total phenols and antioxidant activity) were 
analyzed to know the effect of treatment on its.

\section{Enzyme activity measurement}

Polyphenol oxidase (PPO) was determined according to the method proposed by Tan et al., (2014) with slight modifications. Prepare 0.2 M Sodium phosphate buffer of $\mathrm{pH} 6$ [2.745 $\mathrm{g}$ of sodium dihydrogen phosphate dihydrate $\left(\mathrm{NaH}_{2} \mathrm{PO}_{4} 2 \mathrm{H}_{2} \mathrm{O}\right)$ and $0.427 \mathrm{~g}$ of disodium hydrogen phosphate di-hydrate $\left(\mathrm{Na}_{2} \mathrm{HPO}_{4} 2 \mathrm{H}_{2} \mathrm{O}\right)$ was mixed in $100 \mathrm{ml}$ of double distilled water]. 0.2M Pyrocatechol solution $(0.2 \mathrm{M})$ was used as phenol substrate [0.55 g of pyrocatechol in $25 \mathrm{ml} 0.2 \mathrm{M}$ Sodium phosphate buffer of $\mathrm{pH}$ 6]. A volume of $5.5 \mathrm{ml}$ of buffer and $1.5 \mathrm{ml}$ of $0.2 \mathrm{M}$ pyrocatechol were added into a test tube. The test tube was then immersed in a control temperature water bath at $25^{\circ} \mathrm{C}$ for $2 \mathrm{~min}$ for thermal stabilization. Then add $2 \mathrm{ml}$ of coconut water mix properly and measure the change in absorbance at $420 \mathrm{~nm}$ using UV1700 UV Visible spectrophotometer with respect to the blank solution consist of $7.5 \mathrm{ml}$ buffer and $1.5 \mathrm{ml} 0.2 \mathrm{M}$ pyrocatechol.

Peroxidase (POD) was Determined according to the method proposed by Augusto et al., (2015) with slight modifications. 5\% (w/v) pyrogallol solutions were used as phenol substrate. In each assay $0.32 \mathrm{ml}$ of $5 \%$ pyrogallol solution, $2.36 \mathrm{ml}$ buffer and $0.16 \mathrm{ml}$ coconut water were mixed in a cuvette. Then $0.16 \mathrm{ml}$ of $0.5 \% \mathrm{H}_{2} \mathrm{O}_{2}$ added to this mixture (reaction will start after adding $\mathrm{H}_{2} \mathrm{O}_{2}$ ). The changes in absorbance was measured at 420 $\mathrm{nm}$ with respect to the blank solution contained $0.32 \mathrm{ml} 5 \%$ pyrogallol, $2.52 \mathrm{ml}$ buffer and $0.16 \mathrm{ml} 0.5 \% \mathrm{H}_{2} \mathrm{O}_{2}$.

For both the enzymes, the absorbance was measured at every $5 \mathrm{sec}$ interval for $15 \mathrm{~min}$. then slope of the absorbance curve drawn against time will gives the enzyme activity of coconut water. The enzyme activity was expressed in $\mathrm{U}_{\mathrm{ml}} \mathrm{m}^{-1} \mathrm{~min}^{-1}$ ( $\mu \mathrm{g}$ of protein) ${ }^{-1}$. The relative activity $\left(\mathrm{A}_{\text {rel }}\right)$ can be calculated by using equation 1 .

Relative Activity $\left(\mathrm{A}_{\text {rel }}\right)=\left(\frac{A}{\text { Ao }}\right) \times 100 \ldots \ldots \ldots 1$

Where ' $A$ ' is the enzyme activity of processed coconut water. And ' $\mathrm{A}_{0}$ ' is the initial enzyme activity of unprocessed coconut water.

\section{Measurement of Bioactive Components of Tender Coconut water}

\section{Measurement of ascorbic acid (AA)}

Ascorbic acid (AA) content of TCW was determined by spectrophotometric method based on its ability to decolorize 2, 6dichlorophenol-indophenol dye solution proposed by Ranganna (1991). Briefly, take 1 $\mathrm{mL}$ of sample and make up to $5 \mathrm{~mL}$ with $2 \%$ Metaphosphoric acid $\left(\mathrm{HPO}_{3}\right)$ solution. Then mix with $10 \mathrm{~mL}$ dye solution and measure the absorbance at $518 \mathrm{~nm}$ using UV-visible spectrophotometer against blank (contains 5 $\mathrm{ml} 2 \% \quad \mathrm{HPO}_{3}+10 \mathrm{~mL}$ distilled water). Interference was avoided by rapid determination and the corresponding AA content was obtained from a standard curve drawn for pure L-ascorbic acid (SigmaAldrich) solution (Eqn. 2) which varied within 0.2 to $1 \mathrm{~g} \cdot \mathrm{L}^{-1}$.

Standard AA conc. $\left(\mathrm{mg} \cdot \mathrm{mL}^{-1}\right)=0.783 \times$ (absorbance) (2)

AA of coconut water $\left(m g \cdot m L^{-1}\right)=$ standard AA concentration * final make up volume

Vol. of sample taken

Total phenols by Folin-Ciocalteu reagent (FCR) assay

The methanolic extract of coconut water was used for analysis of total phenols and antioxidant capacity. It was prepared by 
shaking a solution of $5 \mathrm{~mL}$ coconut water with $25 \mathrm{~mL} 80 \%$ methanol in distilled water for $3 \mathrm{~h}$ at ambient temperature $\left(27 \pm 1^{\circ} \mathrm{C}\right)$.

Total phenol content was determined using the Folin-Ciocalteu reagent (FCR) assay according to the method of Singleton et al., (1999) with slight modifications as described by Wijngaard and Brunton (2010). The blue color was developed using a Folin-Ciocalteu reagent (FCR) in an alkaline medium (20\% sodium carbonate) over 90 minutes and its absorbance was measured at $750 \mathrm{~nm}$ in a UVvisible spectrophotometer (Model: UV1700; Make: Shimadzu, Japan). Gallic acid was taken as standard for the phenolic and total phenolic content was expressed in Gallic acid equivalent.

Standard Phenolic conc. $\left(\mathrm{GAE}\right.$ in $\left.\mathrm{mg} \cdot \mathrm{mL}^{-1}\right)=$ $0.2437 \times$ (absorbance)

phenolic concentration of coconut water (GAE in $m g \cdot m L^{-1}$ ) = standard phenolic concentration* volume made up

vol. of methanolic extract taken for estimation * Vol.of sample taken extraction

\section{Antioxidant activity by 2, 2-diphenyl-1- picrylhydrazyl (DPPH) assay}

The antioxidant activity of the extract was measured in terms of its DPPH radical scavenging ability. It represents the ability of the food product to resist oxidation. The advantage of the DPPH method is that free radicals are allowed to react with the whole sample and the relatively longer time given in the method allows the free radical to react slowly even with weak antioxidants (Kedare and Singh, 2011). Methanolic extract of coconut water was used for the analysis of DPPH free radical scavenging activity and it was prepared as described for total phenol content. The DPPH assay was carried out according to the procedure of Goupy et al., (1999) with slight modifications as described by Wijngaard and Brunton (2010). The change in color of the DPPH solution from purple to yellow, resulting from the addition of different quantities of methanolic extract of coconut water or gallic acid (GA) standard (20 to $200 \mu \mathrm{L}$ ) was measured at $517 \mathrm{~nm}$ after allowing the solution to stand in the dark for $30 \mathrm{~min}$. The decrease in absorbance of DPPH after $30 \mathrm{~min}$ was calculated and expressed as mg of GA equivalents antioxidant capacity (GAEAC) per $100 \mathrm{~mL}$ of the sample using the formula given in Eq. (3.9)

GAEAC $=\frac{\Delta A b s_{\text {Sample }}}{\Delta A b s_{G A}} * C_{G A} *\left(\frac{V}{W}\right) * 100$

Where,

$\Delta \mathrm{Abs}_{\text {sample }}$ is the change of absorbance after addition of coconut water extract

$\mathrm{C}_{\mathrm{GA}}$ is the concentration of $\mathrm{GA}$ standard solution $(0.02 \mathrm{mg} / \mathrm{mL})$;

$\Delta \mathrm{Abs}_{\mathrm{GA}}$ is the change of absorbance obtained from a calibration curve when the same volume GA standard solution as that of coconut water extract was added;

$\mathrm{V}$ is the final make up volume of extract; and

$\mathrm{W}$ is the volume of sample used for extraction

\section{Data Analysis}

Analysis of variance (ANOVA) test was conducted using Design expert version 7.0.0 software (State-Ease Inc., Minneapolis, USA) to evaluate the significance (at 95\% confidence level) of the effect of independent variables and their interactions on the responses.

A full factorial design was used to estimate the effect of independent variables (Treatment time, sample thickness and distance sample from lamp source) on responses (PPO, POD, 
Ascorbic acid, Total phenolic content and Antioxidant activity).

\section{Optimization of process parameters}

RSM was applied to the experimental data using Design expert version 7.0.0 software (State-Ease Inc., Minneapolis, USA). The critical responses were screened out based on the effect and importance of responses. The optimization was targeted for maximum inactivation of PPO, POD and minimal changes in nutritional properties of TCW.

\section{Results and Discussion}

\section{Compositions of raw tender coconut water}

The nutritional properties and enzyme activity of TCW were analyzed before treatment. The compositions of TCW varied from fruit to fruit depending upon variety and maturity of fruit (Jackson et al., 2004. Hahn et al., 2012. \& Tan et al., 2014). Although there was important initial difference exists in physicochemical properties of TCW between different verities of fruit. But for comparison these parameters kept as constant for whole experiment. The compositions of fresh TCW were measured and presented in table 1.

\section{Effect of UV Light Treatment on Bioactive Components of Tender Coconut Water}

\section{Effect on ascorbic acid (AA)}

The \% loss in ascorbic acid content in TCW after UV light treatment at different conditions with respect to control (unprocessed tender coconut water) were presented in figure 1 (a-c).

Ascorbic acid is a heat-sensitive bioactive compound that plays a vital role in human health and can act as an antioxidant. The AA content of TCW was found to be in the range of 2.7 to $3.1 \mathrm{mg} / 100 \mathrm{~mL}$. The obtained values of AA are found to be slightly higher than the values reported by molecules et al., 2009. The slight variation in AA might be due to the maturity and variety of TCW (Jackson et al., 2004). From ANOVA data it was showing that the ultraviolet treatment conditions had significant $(\mathrm{p}<0.0001)$ effect on ascorbic acid content in TCW. The ultraviolet treatments at different distances such as 8.6, 13.7 and 18.6 $\mathrm{cm}$ were showed slight changes in \% loss of ascorbic acid at different time intervals (0.090.0 min). Further, at different thickness levels viz., 1, 2 and $3 \mathrm{~mm}$ at a particular distance and time interval for example $8.6 \mathrm{~cm}$ at $90 \mathrm{~min}$ showed negligible changes in \% loss of ascorbic acid. The reason for such kind alternations with thickness and distance were not understood but largely attributed to the fact that the alteration of thickness might causes the penetration of UV light through the sample whereas alterations of distance not showed much effect. The sample which is nearer to the lamp source and having less thickness will receive more energy (Bolton, 1999). The maximum loss (2.96\%) of A.A was observed at $8.6 \mathrm{~cm}$ sample distance, 1 $\mathrm{mm}$ thickness and $90 \mathrm{~min}$ treatment time. The results show that the loss of A.A increases with treatment time. The loss of Ascorbic acid may be due to heating affects with increasing processing time, which results in degradation of ascorbic acid in an aerobic pathway due to its heat-sensitive characteristic in the presence of oxygen. In addition to this, the depletion of ascorbic acid may be due to the formation of free hydroxyl radicals by photochemical reaction, related to oxidative processes. The similar results were reported by Goh et al., (2012). So far there is no review available to compare the loss of A.A value of TCW after ultraviolet treatment. However, similar kinds of studies related to the UV-C effect in other commodities were reported recently (Pala et al., 2013; Tiwari et al., 2009; Alothman et al., 2009(b)). 


\section{Effect on total phenolic content (TPC)}

The total phenolic content values of UV light processed TCW at different treatment conditions were presented in figure 2 (a-c).

Phenolic compounds are beneficial compounds mainly found in fruits and vegetables. They have been implicated in the reduction of degenerative diseases in human beings primarily because of their antioxidant potential.

The TPC of coconut water was found to be in the range of 6.2 to $7.6 \mathrm{mg}$ of $\mathrm{GAE} / \mathrm{L}$. The obtained values of TPC were found to be slightly higher than the values reported by Tan et al., (2014).

The slight variation in TPC might be due to the maturity and variety of TCW (Jackson et $a l ., 2004)$. From ANOVA data it was showing that the ultraviolet treatment conditions had significant $(p<0.0001)$ effect on total phenolic content in TCW.

The ultraviolet treatments at different distances such as 8.6, 13.7 and $18.6 \mathrm{~cm}$ were showed slight increases in total phenolic content at different time intervals (0.0-90.0 min). Further, at different thickness levels viz., 1,2 and $3 \mathrm{~mm}$ at a particular distance and time interval for example $8.6 \mathrm{~cm}$ at 90 min showed negligible changes total phenolic content of TCW.

The reason for such kind alternations with thickness and distance were not understood but largely attributed to the fact that the alteration of thickness might causes the penetration of UV light through the sample whereas alterations of distance not showed much effect. The sample which is nearer to the lamp source and having less thickness will receive more energy (Bolton et al., 1999). Application of UV can either enhance or decrease the antioxidants, which are entirely dependent on the exposure time, delivered dose, solvents used and the basic raw material.

In this study, methanol was used as an extracting solvent as it has been shown to exhibit potentially high antioxidant activities (Ndhlala et al., 2008).

Different behavior of TPC content was reported by different authors in literature. For example, Noci et al., (2008) found a significant decrease in total phenol content of apple juice after UV-C treatment. On the other hand, Caminiti et al., (2012) reported that there were no significant changes in total phenol content of apple juice exposed to UVC light.

Moreover, Pala et al., (2011a) reported that there were no significant changes in total phenol content of pomegranate juice subjected to UV-C light.

\section{Effect on antioxidant capacity}

The GAE Antioxidant capacity of coconut water values after UV light and thermal treatment at different conditions were presented in figure $3(a-c)$.

The GAE Antioxidant capacity of coconut water was found to be in the range of 0.75 to $0.82 \mathrm{mg}$ of GAEAA/L. From ANOVA data it was showing that there was slight increase in Antioxidant capacity of TCW after UV treatment.

The stress response induced by UV-C processing may increase extraction of antioxidant compounds. On other hand the thermal treatment causes the reduction in antioxidant capacity in TCW. The increase in antioxidant activity after ultraviolet treatment was reported by Bhat et al., (2011). 


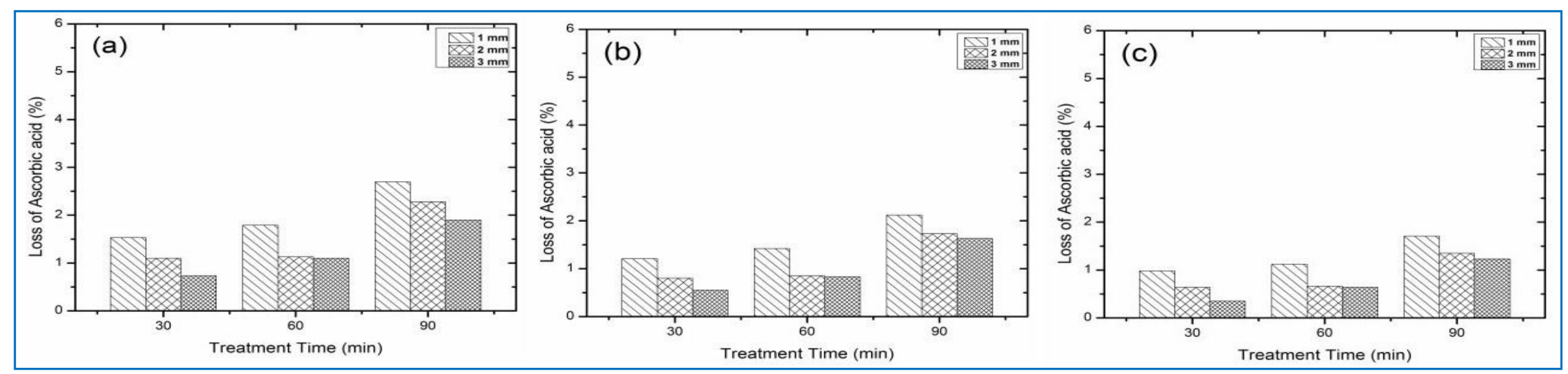

Fig.1 Effect of different treatment conditions on ascorbic acid of TCW (a) UV, $8.6 \mathrm{~cm}$ (b) UV, $13.7 \mathrm{~cm}$ (c) UV, $18.6 \mathrm{~cm}$

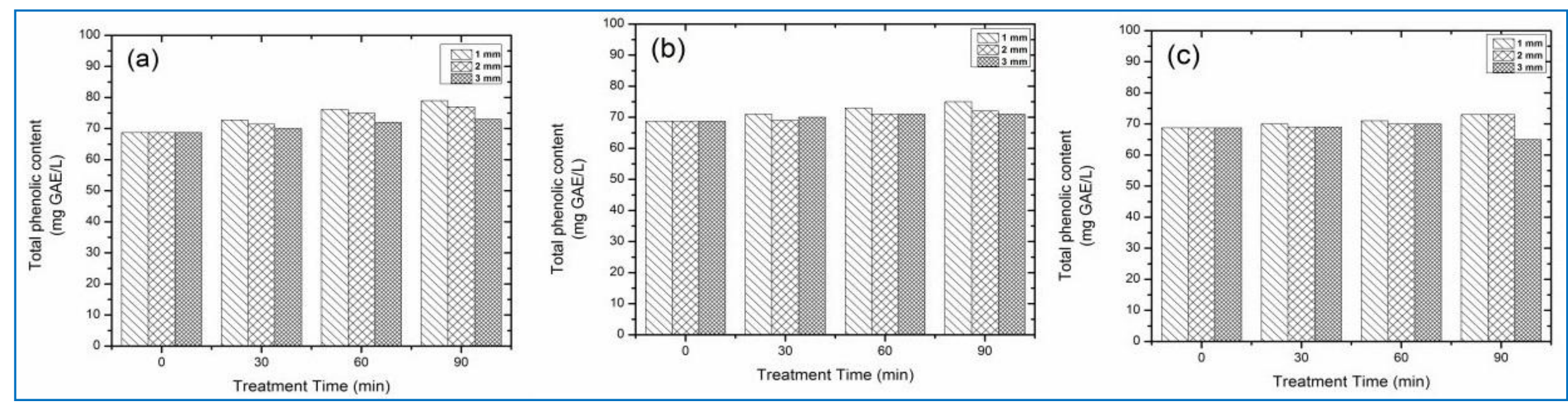

Fig.2 Effect of different treatment conditions on total phenolic content of TCW (a) UV, 8.6 (b) UV, 13.7 (c) UV, $18.6 \mathrm{~cm}$ 


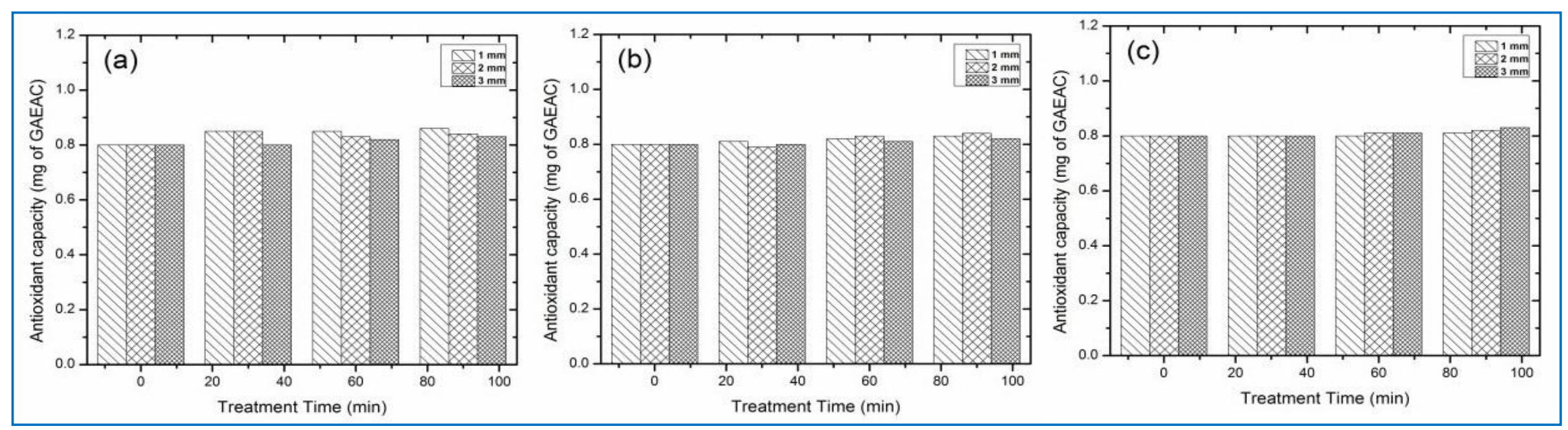

Fig.3 Effect of different treatment conditions on antioxidant capacity of TCW (a) UV, 8.6 (b) UV, 13.7 (c) UV, $18.6 \mathrm{~cm}$

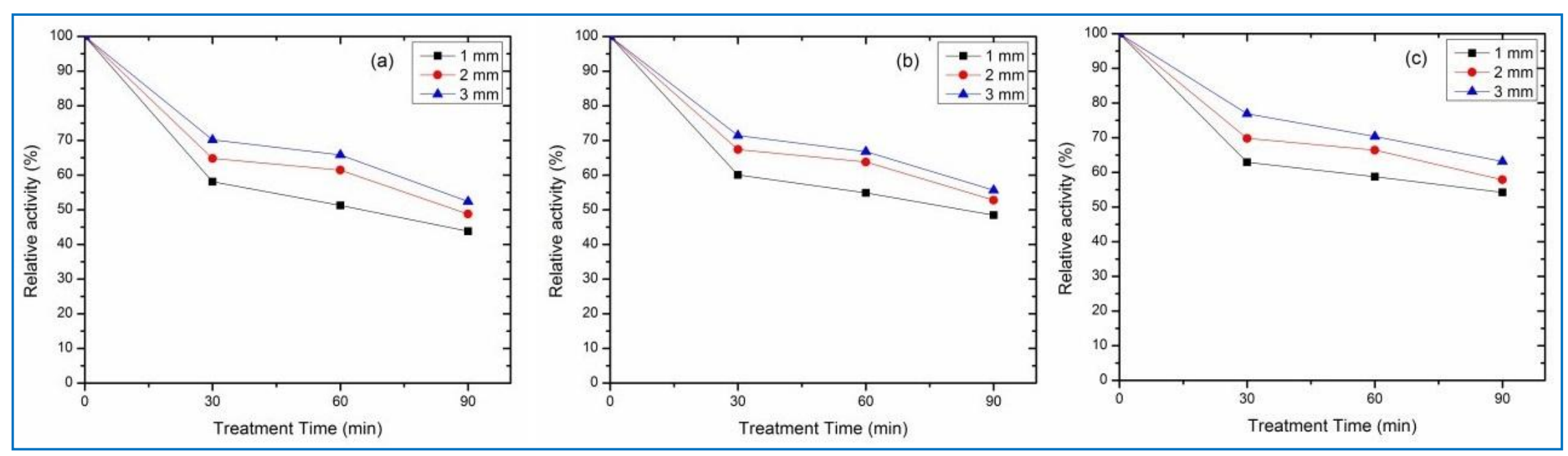

Fig.4 Effect of different treatment conditions on PPO activity of TCW (a) UV, 8.6 (b) UV, 13.7 (c) UV, $18.6 \mathrm{~cm}$ 


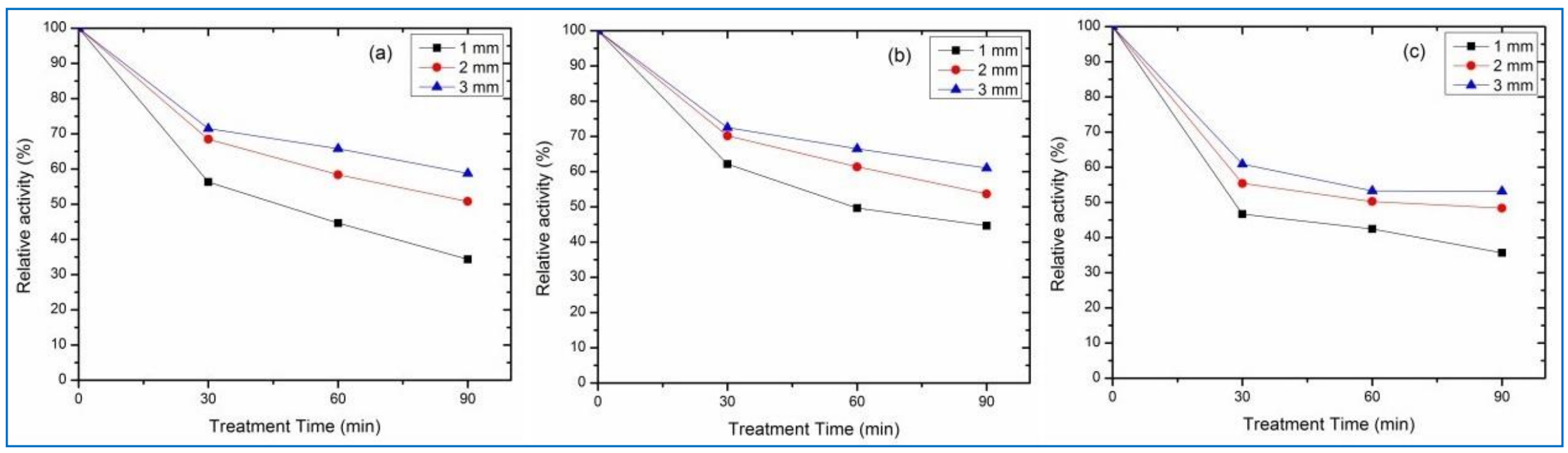

Fig.5 Effect of different treatment conditions on PPO activity of TCW (a) UV, 8.6 (b) UV, 13.7 (c) UV, $18.6 \mathrm{~cm}$

Table.1 Enzyme activity and biochemical characterization of tender coconut water

\begin{tabular}{ll}
\hline Parameters & Value \\
\hline Ascorbic acid & $2.7 \pm 0.25$ \\
Total phenolic content (mg of GAE/ L) & $63.1 \pm 0.4$ \\
Antioxidant activity $(\mathrm{mg}$ of GAEAC/ L) & $8.1 \pm 0.5$ \\
PPO $\left(\mathrm{U} \cdot \mathrm{mL}^{-1} \cdot \mathrm{min}^{-10} \mathrm{Brix}^{-1}\right)$ & $0.59 \pm 0.015$ \\
POD $\left(\mathrm{U} \cdot \mathrm{mL}^{-1} \cdot \mathrm{min}^{-10} \mathrm{Brix}^{-1}\right)$ & $0.06 \pm 0.024$ \\
\hline \multicolumn{2}{c}{ Note: Values reported as mean \pm standard deviation $(\mathrm{N}=12)}$.
\end{tabular}


Table. 2 Constraints for optimization of ultraviolet process parameters

\begin{tabular}{|c|c|c|c|c|}
\hline Variables & Condition & Lower Limit & Upper Limit & Importance \\
\hline Treatment time (min) & Minimize & 30 & 90 & 4 \\
\hline Sample thickness (mm) & Maximize & 1 & 3 & 3 \\
\hline $\begin{array}{l}\text { Distance of sample from } \\
\text { lamp source }(\mathrm{cm})\end{array}$ & Minimize & 8.6 & 18.6 & 2 \\
\hline Responses & Condition & Lower Limit & Upper Limit & Importance \\
\hline $\begin{array}{l}\text { Relative activity of PPO } \\
(\%)\end{array}$ & Minimize & 48.82 & 85.2 & 4 \\
\hline Relative activity of POD & Minimize & 34.3 & 76.2 & 4 \\
\hline Loss of Ascorbic acid (\%) & Minimize & 0.35 & 2.7 & 3 \\
\hline $\begin{array}{l}\text { Total phenolic content (mg } \\
\text { of GAE/L) }\end{array}$ & Maximize & 69 & 79 & 3 \\
\hline $\begin{array}{l}\text { Antioxidant capacity (mg } \\
\text { of GAEAC/L) }\end{array}$ & Maximize & 0.6 & 0.8 & 3 \\
\hline
\end{tabular}

Table.3 Predicted optimum values for ultraviolet variables and responses

\begin{tabular}{ccccccccccc}
\hline S.No & $\begin{array}{c}\text { Time } \\
(\mathrm{min})\end{array}$ & $\begin{array}{c}\text { Thickness } \\
(\mathrm{mm})\end{array}$ & $\begin{array}{c}\text { Distance } \\
(\mathrm{cm})\end{array}$ & $\begin{array}{c}\text { R.A } \\
\text { of } \\
\text { PPO } \\
(\%)\end{array}$ & $\begin{array}{c}\text { R.A } \\
\text { of } \\
\text { POD }\end{array}$ & $\begin{array}{c}\text { A.A } \\
(\%)\end{array}$ & $\begin{array}{c}\text { TPC } \\
(\mathrm{mg} \text { of } \\
\text { GAE/L) }\end{array}$ & $\begin{array}{c}\text { Antioxidan } \\
\text { t capacity } \\
(\mathrm{mg} \text { of } \\
\text { GAEAC/L) }\end{array}$ & $\begin{array}{c}\text { Turbidity } \\
(\%)\end{array}$ & Desirability \\
\hline $1^{*}$ & 30 & 1.27 & 8.6 & 63.45 & 53.24 & 0.95 & 72.14 & 0.76 & 3.6 & 0.647 \\
2 & 30 & 1.31 & 8.6 & 64.2 & 55.42 & 0.955 & 73.2 & 0.77 & 3.51 & 0.647 \\
\hline
\end{tabular}

* Selected for further studies

\section{Effect of UV Light Treatment on Enzyme Activity of Tender Coconut Water}

\section{Effect on Polyphenol oxidase (PPO)}

The relative activity of PPO (with respect to control) of UV light processed TCW at different conditions were presented in figure 4 (a-c).

Generally, Polyphenol oxidases (PPO) are copper containing oxidoreductases that catalyze the hydroxylation and oxidation of phenolic compounds in the presence of molecular oxygen. The PPO activity of TCW was found to be in the range of 0.58 to 0.62 $\left(\mathrm{U} \cdot \mathrm{mL}^{-1} \cdot \mathrm{min}^{-10} \mathrm{Brix}^{-1}\right)$. The obtained values of PPO were found to be within the reported range in the literature (Tan et al., 2014).From ANOVA data it was showing that the ultraviolet treatment conditions had significant $(\mathrm{p}<0.0001)$ effect on PPO activity in TCW. The ultraviolet treatments at different distances such as 8.6, 13.7 and 18.6 $\mathrm{cm}$ were showed slight decrease in relative activity of PPO at different time intervals (0.0-90.0 min). Further, at different thickness levels viz., 1,2 and $3 \mathrm{~mm}$ at a particular distance and time interval for example $8.6 \mathrm{~cm}$ at 90 min showed great changes in relative activity of PPO. The reason for such kind alternations is, the sample which is nearer to the lamp source and having less thickness will receive more energy (Bolton et al., 1999). The minimum activity of PPO obtained at 90 min treatment time, $1 \mathrm{~mm}$ sample thickness 
and $8.6 \mathrm{~cm}$ sample distance from lamp source. So far the exact mechanism for inactivation of enzymes using UV light treatment was not mentioned by any authors. The probable mechanisms reported by Augusto et al., (2006). The inactivation of enzymes may be due to, when enzyme is exposed to the radiation; the absorbed energy leads to changes on its spatial-structure, in general a partial molecular unfolding. These configurations result in inactivation of enzymes.

\section{Effect on Peroxidase (POD)}

The relative activity of POD of UV light processed TCW at different conditions was presented in figure $5(\mathrm{a}-\mathrm{c})$. POD activity of TCW was found to be in the range of 0.06 to 0.078 (U.mL ${ }^{-1}$. $\min ^{-10} \mathrm{Brix}^{-1}$ ). The obtained values of POD were found to be within the reported range in the literature (Tan et al., 2014). The results show that the relative activity of POD is lesser than the relative activity of PPO. From ANOVA data it was showing that the ultraviolet treatment conditions had significant $(p<0.0001)$ effect on POD activity in TCW. The ultraviolet treatments at different distances such as 8.6, 13.7 and $18.6 \mathrm{~cm}$ were showed slight decrease in relative activity of PPO at different time intervals (0.0-90.0 min).Further, at different thickness levels viz., 1, 2 and $3 \mathrm{~mm}$ at a particular distance and time interval for example $8.6 \mathrm{~cm}$ at $90 \mathrm{~min}$ showed great changes in relative activity of PPO. The reason for such kind alternations is the sample which is nearer to the lamp source and having less thickness will receive more energy (Bolton et al., 1999).The minimum activity of POD obtained at $90 \mathrm{~min}$ treatment time, $1 \mathrm{~mm}$ sample thickness and $8.6 \mathrm{~cm}$ sample distance from lamp source. So far the exact mechanism for inactivation of enzymes using UV light treatment was not mentioned by any authors. The probable mechanisms reported by Augusto et al., (2006). The inactivation of enzymes may be due to, when enzyme is exposed to the radiation; the absorbed energy leads to changes on its spatial-structure, in general a partial molecular unfolding. These configurations result in inactivation of enzymes.

\section{Optimization of process parameters}

Optimization condition for ultraviolet and thermal treated coconut was determined with the help of commercial software (Design Expert Version 7.0.0). The optimization of ultraviolet treatment conditions was aimed to maximum inactivation of enzymes (viz. PPO and POD) which cause browning and off flavor, maximum retention of Ascorbic acid, Total phenolic content and Antioxidant activity. The detailed parameters with their importance and the obtained optimized condition are shown in tables 2 and 3 respectively.

In conclusion, effect of ultraviolet (UV-C) of tender coconut water (Cocos nucifera) on Enzymes (PPO and POD) and nutritional properties (viz. Ascorbic acid, Total phenolic content and Antioxidant activity) were studied during this research work. The process conditions for ultraviolet treatment were sample thickness $(1,2,3 \mathrm{~mm})$, treatment time $(30,60,90 \mathrm{~min})$ and distance of sample from lamp source $(8.6,13.7,18.6 \mathrm{~cm})$. The results obtained from this study showed that the ultraviolet treatment (UV) have any significant effect on PPO, POD, Ascorbic acid, Total phenolic content and Antioxidant activity of tender coconut water (TCW). Further, the results were compared with enzyme activity and nutritional properties of tender coconut water after thermal processing in literature. The results indicate that the maximum inactivation of PPO and POD was achieved in thermal treatment than the ultraviolet treatment. In contrast, the 
deterioration of nutritional properties in thermal treatment was high as compared to ultraviolet treatment. The obtained results suggested that, although the thermal treatment was better processing option pertaining to enzyme inactivation, but ultraviolet treatment was found superior based on retention of nutritional attributes.

\section{Acknowledgment}

The authors express sincere thanks to IIT Kharagpur and ministry of MHRD, Govt. of India for providing financial support during the tenure of research work.

\section{References}

Augusto, P. E., Ibarz, R., Garvín, A., \&Ibarz, A. (2006). Peroxidase (POD) and polyphenol oxidase (PPO) photoinactivation in a coconut water model solution using ultraviolet (UV).

Food Research International, 74, 151159.

Bhat, R., Ameran, S. B., Voon, H. C., Karim, A. A., \&Tze, L. M. (2011). Quality attributes of starfruit (Averrhoa carambola L.) juice treated with ultraviolet radiation. Food Chemistry, 127(2), 641-644.

Bintsis, T., Litopoulou- Tzanetaki, E., \& Robinson, R. K. (2000). Existing and potential applications of ultraviolet light in the food industry-a critical review. Journal of the

Science of Food and Agriculture, 80(6), 637-645.

Bolton, J.R. Ultraviolet Applications Handbook, 1st Ed. 1999, Ayr, Ontario, Canada, Bolton Photosciences, Inc

Campos, C. F., Souza, P. E. A., Coelho, J. V., \&Glória, M. B. A. (1996). Chemical composition, enzyme activity and effect of enzyme inactivation on flavor quality of green coconut water.
Journal of Food Processing and Preservation, 20(6), 487-500.

Canitez N., 2002. Pasteurization of Apple Cider with UV Irradiation. MS Thesis. The University of Maine

Chan E., Elevitch CR. Species profiles for Pacific isaland agroforestry, 2006. [Online]. Available www.traditionaltree.org.

Chowdhury, M. M., Aziz, M. G., \& Uddin, M. B. (2005). Development of shelfstable ready-to-serve green coconut water. Biotechnology, 4(2), 121-125.

Falguera, V., Pagán, J., \&Ibarz, A. (2011). Effect of UV irradiation on enzymatic activities and physicochemical properties of apple juices from different varieties. LWT-Food Science and Technology, 44(1), 115-119.

Gabriel, A. A., \& Nakano, H. (2009). Inactivation of Salmonella, E. coli and Listeria monocytogenes in phosphatebuffered saline and apple juice by ultraviolet and heat treatments. Food Control, 20, 443-446.

Goh, S. G., Mohd Adzahan, N., Leong, C. M., Sew, C. C., \&Sobhi, B. (2012). Effect of thermal and ultraviolet treatments on the stability of antioxidant compounds in single strength pineapple juice throughout refrigerated storage. International Food

Research Journal, 19(3), 1131-1136.

Goupy, P., Hugues, M., Boivin, P. and Amiot, M. J. (1999). Antioxidant composition and activity of barley (Hordeum vulgare) and malt extracts and of isolated phenolic compounds. Journal of the Science of Food and Agriculture, 79(12): 1625-1634.

Hahn, F. (2012). An on-line detector for efficiently sorting coconut water at four stages of maturity. Biosystems Engineering, 111(1), 49-56.

Jackson, J. C., Gordon, A., Wizzard, G., McCook, K., \& Rolle, R. (2004). 
Changes in chemical composition of coconut (Cocos nucifera) water during maturation of the fruit. Journal of the Science of Food and Agriculture, 84(9), 1049-1052.

Kedare, S.B. and Singh, R.P. (2011). Genesis and development of DPPH method of antioxidant assay. Journal of Food Science and Technology, 48(4): 412422.

Krishnankutty S. 2005. Coconut Development Board (CDB), India.

Miller, R.V., Jeffrey, W., Mitchell, D. and Elasri, M., 1999. Bacterial responses to ultraviolet light, American Society of Microbiology News65 (8):535-541.

Noci, F., Riener, J., Walkling-Ribeiro, M., Cronin, D. A., Morgan, D. J., \&Lyng, J. G. (2008). Ultraviolet irradiation and pulsed electric fields (PEF) in a hurdle strategy for the preservation of fresh apple juice. Journal of Food Engineering, 85(1), 141-146.

Pala, C. U., \&Toklucu, A. K. (2011). Effect of UV-C light on anthocyanin content and other quality parameters of pomegranate juice. Journal of Food Composition and Analysis, 24(6), 790-795.

Ranganna S. (1991). Handbook of Analysis and Quality Control for Fruit and Vegetable Products. Tata McGraw-Hill Publishing Co. Ltd, New Delhi.3-19.
Tan, T. C., Cheng, L. H., Bhat, R., Rusul, G., \&Easa, A. M. (2014). Composition, physicochemical properties and thermal inactivation kinetics of polyphenol oxidase and peroxidase from coconut (Cocos nucifera $\mathrm{L}$ ) water obtained from immature, mature and overly-mature coconut. Food Chemistry, 142, 121-128.

Tan, T. C., Cheng, L. H., Bhat, R., Rusul, G., \&Easa, A. M. (2015). Effectiveness of ascorbic acid and sodium metabisulfite as anti-browning agent and antioxidant on green coconut water (Cocos nucifera $\mathrm{L}$ ) subjected to elevated thermal processing. International Food Research Journal, 22(2), 631-637.

Walter, E. H. M., Nascimento, M. S., \&Kuaye, A. Y. (2009). Efficacy of sodium hypochlorite and peracetic acid in sanitizing green coconuts. Letters in Applied Microbiology, 49(3), 366-371.

Wijngaard, H. H. and Brunton, N. (2010). The optimization of solid-liquid extraction of antioxidants from apple pomace by response surface methodology. Journal of Food Engineering, 96(1): 134-140.

Yong, J. W., Ge, L., Ng, Y. F., \& Tan, S. N. (2009). The chemical composition and biological properties of coconut (Cocos nucifera L.) Water Molecules, 14(12), 5144-5164.

\section{How to cite this article:}

Shivashankar Sanganamoni, Soumya Purohit and Srinivasa Rao, P. 2017. Effect of UltravioletC Treatment on Enzymes and Nutritional Properties of Tender Coconut Water. Int.J.Curr.Microbiol.App.Sci. 6(5): 2905-2918. doi: https://doi.org/10.20546/ijcmas.2017.605.330 